\title{
ABORTO: NOVOS ENTENDIMENTOS X NOVAS VIDAS.
}

Beatriz Guimarães Cabral, Sergio Mastellini.

Universidade do Oeste Paulista - UNOESTE, Curso de Direito, Presidente Prudente, SP. E-mail: this guimaraes@hotmail.com.

\section{RESUMO}

Diante dos argumentos do Supremo Tribunal Federal, para o novo entendimento a respeito da não criminalização do aborto até o terceiro mês de gestação, o artigo a ser analisado, traz consigo inúmeras controversas de maneira a erradicar tal decisão. O aborto não provoca consequência somente ao feto, ocasionando a sua morte, como também na mulher que o realiza e a sociedade. Aquela, pode-se dizer que é a mais afetada, pois quando o ato não resulta em sua morte também, poderá surgir sequelas tanto física quanto mental, necessitando de acompanhamentos com profissionais da psicologia para esses últimos. Dessa forma, analisaremos cada caso em tela e concluiremos que o melhor é não o realizar, prevalecendo o maior direito tutelado, a vida.

Palavras Chaves: Aborto. Consequências. Vida. Mudanças. Erradicar.

\section{ABORTION: NEW UNDERSTANDINGS X NEW LIVES.}

\begin{abstract}
Faced with the arguments of the Federal Supreme Court, for the new understanding regarding the non-criminalization of abortion until the third month of gestation the article to be analyzed brings with it numerous controversies in order to eradicate such a decision. Abortion does not only result in the fetus, causing its death, but also in the woman who performs it and society. It can be said that it is the most affected, because when the act does not result in its death also, it can appear both physical and mental sequelae, needing accompaniments with professionals of psychology for the latter. In this way, we will analyze each case on the screen and conclude that it is best not to carry it out, with the highest right being protected, life.
\end{abstract}

Keywords: Abortion. Consequences. Life. Changes. Eradicate. 


\section{INTRODUÇÃO}

O aborto apresenta inúmeras controvérsias de pensamentos e opiniões. Nenhuma delas é dita como errada, pois o raciocínio é algo individual, porém deve haver cautela ao analisar o assunto.

O bem jurídico aqui tutelado, como também protegido pela nossa legislação maior, a Constituição Federal, é a Vida. Como tirar de alguém indefeso, o direito de nascer e viver? Não sendo o aborto necessário (para salvar a vida da gestante, por exemplo) ou legal, gravidez resultante de estupro, não há argumentos convincentes para esse ato.

A vida de todos, em especial a do embrião e sua genitora (pois esta, em muitos casos não sobrevive) devem ser prioridade em qualquer situação. Diniz (apud COSTA, 2005, p. 38), afirma:

A vida é igual para todos os seres humanos. Como então, se poderia falar em aborto? Como admitir o aborto, em que a vitima é incapaz de defendese, não pode clamar por seus direitos? Como acatar o aborto que acoberta em si seu verdadeiro conceito jurídico: assassinato? Se toda vida humana goza da mesma inviolabilidade constitucional, como seria possível a edição de uma lei contra ela? A vida extrauterina teria um valor maior do que a preocupação com a coerência lógica, rebaixando o direito de nascer?

O presente estudo diz respeito aos novos entendimentos do Supremo Tribunal Federal a respeito da não criminalização do aborto até o terceiro mês de gestação.

Trataremos acerca do mal que tal ato resulta, não somente ao embrião que é o maior prejudicado como também a mulher que o realiza, pois quando não é levada a óbito, poderá ficar com sequelas tanto no corpo quando no psicológico, necessitando de acompanhamentos médicos a fim de sanar o distúrbio por ela frequente. De acordo com Elizabeth Saar, 2005:

Estima-se que a cada ano ocorram de 750 mil a 1 milhão de abortos clandestinos no Brasil. Em média, 250 mil mulheres são internadas pelo Sistema Único de Saúde (SUS) vítimas de abortos inseguros. Delas, cerca de $10 \%$ morrem, influindo significativamente nos índices de mortalidade materna, e $20 \%$ ficam com sequelas.

O depoimento de uma mulher vítima desses transtornos, ou seja, que passa por tais desafios mesmo após 8 (oito) anos da realização do aborto será apresentado para termos ciência do quão prejudicial é. Não sendo o suficiente, a prática do aborto resulta em males também para a sociedade, argumentado no interior do texto.

Apresento também, como sendo de suma importância, as atitudes que o Estado deve ter de maneira a prevenir a realização do ato, como preservativos a serem distribuídos gratuitamente, palestras nas escolas, pois o alvo maior são os jovens e o resultado vai muito além de uma gravidez interrompida, são vidas, sonhos "jogados fora".

Contudo, o objetivo do presente trabalho é a incansável defesa da vida, diante dos novos argumentos utilizados pelo Supremo Tribunal Federal para a imposição do novo entendimento e apresentação dos incômodos físicos e psíquicos causados a mulher, ao principal prejudicado, o feto e os danos à sociedade.

\section{METODOLOGIA}

O projeto a ser apresentado traz consigo pesquisas classificadas como explicativa por meio da abordagem direta, realizado por pesquisas bibliográficas e de campo. O método utilizado será o dedutivo, ou seja, aquele que advém de Leis Gerais, para aplicar a uma particularidade, em outras palavras, atingir algo específico. Não obstante, será o documento realizado por meio de orientações e diversas pesquisas. A base do presente estudo é orientar o leitor sobre a prevenção 
e a conscientização que o aborto não é a "única" solução por muitos enxergada. O direito à vida deve ser preservado.

\section{RESULTADOS}

O Aborto é uma maneira de interromper a vida uterina e segundo o Código Penal especificadamente em seu artigo 124 e ss, é um crime o qual somente não será punido aquele provocado por médico para salvar a vida da gestante ou fruto do estupro. Porém o HABEAS CORPUS 124.306 afastou a prisão preventiva à gestante que autoriza, bem como aos corréus que praticam o ato até o terceiro mês de gestação.

"É uma prática polêmica e complexa, pois envolvem aspectos religiosos, sociais, políticos, demográficos, pessoais e muitos outros" (NOGUEIRA, 1995, p. 3). Este, afirma ainda, que no ano da publicação de sua obra utilizada como referência no presente artigo, ou seja, em 1995, cerca de 300 (trezentas) mulheres por ano realizavam o aborto. Após pesquisas avançadas, ficou constatado que em 2014, esse índice se elevou muito, sendo 850 (oitocentas e cinquenta) mil mulheres por ano. Vale ressaltar também que é a quinta maior causa de morte materna no Brasil.

O mesmo está englobado até nos gastos da Seguridade Social - art. 194 da CF. Poderia esta utilizar o dinheiro com outros meios de priorizar a saúde pública, como aparelhos médicos, por exemplo, ou qualquer outra contribuição para o país, porém tem que concentrar boa parte em algo que poderia ser evitado. Confirmando assim, um dos problemas que o aborto oferece.

Diante da Inconstitucionalidade da criminalização do aborto praticado por voluntariedade da gestante até o terceiro trimestre, devem ser realizados meios para que seja evitado e assim não haveria os problemas citados acima, como muitos outros não apresentados. Dessa forma:

É papel do Estado e da sociedade atuar nesse sentido, mediante oferta de educação sexual, distribuição de meios contraceptivos e amparo à mulher que deseje ter o filho e se encontre em circunstâncias adversas. Portanto, ao se afirmar aqui a incompatibilidade da criminalização com a Constituição, não se está a fazer a defesa da disseminação do procedimento. Pelo contrário, o que ser pretende é que ele seja raro e seguro. (HC 124.306, Rel. Min. Luís Roberto Barroso, 2016, p. 6).

Tais cautelas providenciadas pelo Estado devem ser adotadas por todos, em especial as mulheres que não pretendem ter filhos ou não possuem condições, seja ela financeira, emocional, entre outras. O pensamento de que o aborto "esta ai para ser feito" deve ser excluído, uma vez que foi legalizado até o 30 mês de gestação, não é digno de ser realizado com tanta frequência, pois se assim fosse, como ficará a estatística quando forem colhidos os dados de quantos abortos foram feitos no ano de 2017 e seguintes com a nova ordem de não criminalização?

\section{DISCUSSÃO}

A vida além de ser um bem precioso é direito de todos, sendo ele o mais defendido e assegurado pela Constituição Federal:

Art. 5o Todos são iguais perante a lei, sem distinção de qualquer natureza, garantindo-se aos brasileiros e aos estrangeiros residentes no País a inviolabilidade do direito à vida, à liberdade, à igualdade, à segurança e à propriedade, nos termos seguintes. (Grifo nosso). (BRASIL, Constituição Federal, 1988).

Muitas famílias, em especial as mulheres que o praticam, futuramente se arrependem, necessitam de acompanhamentos com psicólogo, pois sua saúde fica afetada ao se questionarem 
o porquê fizera tal ação, mentalizando que a vida acabou. O depoimento a seguir nos apresenta o desespero de uma mulher que lamenta a realização do aborto.

"Aos 19 anos, fiquei grávida. Contei ao meu namorado e ele me disse que preferia ter o filho. Já minha mãe não teve dúvidas: falou que eu teria de tirar o bebê. Na época, eu cursava prévestibular e não trabalhava, mas tinha dúvidas se queria abortar ou não. Tomei a decisão quando percebi meu corpo mudando. Pensei: tem uma criança dentro de mim!Falei para minha mãe que não queria abortar, mas ela foi enfática: se insistisse nisso eu iria para o olho da rua. Cedi à pressão e fui a uma clínica que uma amiga dela indicou. Quando chegamos lá, me examinaram e marcaram para aquela noite. Minha mãe não pôde ir porque tinha prova na faculdade. Eu já não estava mais falando com o meu namorado, que nunca gostou da ideia do aborto. Então, fui sozinha. Fiquei em uma sala com oito garotas. Uma ia abortar pela quarta vez. Outra tinha traído o noivo e ficado grávida. Fui a primeira a ser chamada. Tomei anestesia e apaguei. Quando acordei, me avisaram que poderia ir embora e que era normal ter sangramento na primeira semana. Quando cheguei em casa, bateu o arrependimento e saí quebrando o que via na frente. Sangrei um mês inteiro. Meu ginecologista encontrou restos placentários dentro de mim. Me internaram para fazer o esvaziamento do útero. Fui levando uma vida normal, até retomar meu namoro no ano seguinte, quando comecei a sentir dores por todo o corpo e a me entupir de remédios. Acabei no hospital e o namoro terminou de novo. Depois dessa crise, comecei a fazer terapia para tratar minha culpa. Quase não falo mais com minha mãe. Há dois anos, me casei, mas não penso ainda em ter filhos. Às vezes, quando vejo uma criança, penso no bebê que poderia ter tido, em como ele seria. Jamais me esquecerei do que fiz. Jamais esquecerei do que fiz. Quando vejo uma criança, penso em como seria o meu bebê". Renata, 27 anos, publicitária.

Não são todas as mulheres que conseguem falar a respeito, como fez Renata. O ideal seria para outras terem como exemplo ao pensar em praticar. Certamente ao ouvir, ler um depoimento de quem já realizou e hoje se arrepende, iria pensar mais sobre sua decisão e chegar à conclusão que não é certo, protegendo o direito do nascituro, ou melhor, o direito de todos, sendo esse, o direito à vida. Muitas o praticam de maneira restrita, sem nem contar ao parceiro (quando tem), ou aos pais, familiares e amigos íntimos. Ao saberem da gravidez, decidem realizar o aborto e o faz de maneira não alarmante, logo após, reagem da mesma forma, não conseguem falar sobre, guardam em seu interior, achando que encontrou uma maneira de esconder de todos, até de si mesma.

Para muitas mulheres, valores e crenças religiosas contrapõem-se à possibilidade de decidir por um aborto. Instala-se assim uma situação de tensão entre esses valores e a solução representada pelo recurso ao aborto. Entretanto, mesmo uma mulher que esteja segura da validade moral de sua decisão por interromper a gravidez, enfrenta o peso do tratamento social dessa sua escolha. Estigma social, vergonha e medo são associados às práticas abortivas. Há uma associação implícita entre contracepção e comportamento responsável; interrupção da gravidez e comportamento irresponsável. Além do peso de os abortos serem, em sua maior parte, praticados na ilegalidade e na clandestinidade. Torna-se assim difícil para as mulheres partilharem suas experiências nesse campo. E é no silêncio e no isolamento que as vivem. Ainda que, em certas circunstâncias, o aborto apresente-se para elas como a solução de um problema - uma gravidez impossível de ser levada a termo -, devem falar dele como algo trágico e lamentável. (XAVIER, 2006, p. 35).

Temos que nos conscientizar e conscientizar a sociedade que o aborto deverá ser realizado somente nos casos quem o art. 128 Código Penal dispõe, são eles: 
Art. 128 - Não se pune o aborto praticado por médico:

Aborto necessário

I - se não há outro meio de salvar a vida da gestante;

Aborto no caso de gravidez resultante de estupro

II - se a gravidez resulta de estupro e o aborto é precedido de consentimento da gestante ou, quando incapaz, de seu representante legal. (BRASIL, Código Penal, 1940).

Quando se trata de gravidez em que pode causar a morte da gestante, o aborto poderá ser realizado, não deixará de ser uma vida interrompida, como citado anteriormente, porém o legislador julga ser o correto, pois se presumem que a gestante tem família que necessita do seu amparo, muitas vezes outros filhos para selar. Uma mulher é independente, diferente da criança que depende totalmente de um adulto para sua sobrevivência. Porém o inciso em questão não abrande somente ao risco presente.

De acordo com a interpretação literal da mencionada expressão legal, entende-se ser exigível que a gestante esteja à beira da morte para que a interrupção da gravidez seja justificada. Todavia, a descriminante em menção não se refere apenas a casos extremos de iminência de morte para a gestante.

Na verdade, como já afirmou jurista Nelson Hungria, "o aborto necessário pode ser terapêutico (curativo) ou profilático (preventivo), ou seja, é possível a prática do abortamento necessário, diante de um risco iminente de morte, mas, também, para prevenir situação futura que exponha a perigo a vida da gestante. Como se vê, a situação prevista na descriminante e menção expressa aquela situação óbvia de extremo e iminente risco de vida" (FAÚNDES; TORRES, 2002, p. 148).

Outra hipótese da pratica legal do aborto, é quando a gravidez resulta de estupro. Nesse caso, a mulher gera em si o fruto de um ato violento, o qual traz perturbações em sua mente e em seu cotidiano. Porém, para que o aborto seja realizado deve ser consentido pela mesma, caso esta preferir levar adiante e dar à luz a criança, assim deve proceder, salvo se menor de idade, pois nessa situação será o representante legal que estabelecerá.

Compêndio, Diniz (apud COSTA, 2005, p. 38), nos afirma o até aqui estudado e questiona:

A vida é igual para todos os seres humanos. Como então, se poderia falar em aborto? Como admitir o aborto, em que a vitima é incapaz de defendese, não pode clamar por seus direitos? Como acatar o aborto que acoberta em si seu verdadeiro conceito jurídico: assassinato? Se toda vida humana goza da mesma inviolabilidade constitucional, como seria possível a edição de uma lei contra ela? A vida extrauterina teria um valor maior do que a preocupação com a coerência lógica, rebaixando o direito de nascer?

Portanto, o novo entendimento do STF a respeito da não criminalização até o terceiro mês de gestação, deve ser analisado à risca. Em suma, o aborto tem como sua maior vítima o embrião, pois lhe resulta a morte, porém não é o único, como citado em outra oportunidade, podendo gerar também complicações no corpo da mulher e até mesmo a evolução a óbito, resultando duas vítimas, duas vidas, em "apenas" um ato.

\section{CONCLUSÃO}

É alarmante e também intrigante o aumento do número de aborto ocorrido entre 19 (dezenove) anos elencado no início deste, e mais apavorante será os novos algarismos das 
pesquisas a serem levantadas após a sua liberação até a décima segunda semana de gestação. 0 Brasil é considerado o pais que mais concentra a realização desse ato, imaginemos então como ficará o IDH (Índice de desenvolvimento Humano) nos próximos anos. Lastimável.

A Constituição assegura um Direito considerado o mais importante deles, sendo este, a vida. Todos têm direito a ela e o único que pode responder por continuá-la ou não, é o próprio individuo, o seu titular. Ora, se outrem não pode decidir, como permitir a realização do aborto se o feto não é capaz de opinar. Ele possui desde o ventre o Direito aqui elencado, e deve ser respeitado.

\section{REFERÊNCIAS}

CAVALCANTE, A.; XAVIER, D. Em defesa da vida: aborto e direitos humanos. 1. ed. São Paulo: Católicas pelo direito de decidir, 2006.

COSTA, C. Aborto: direito ou crime?. 2005. 52. Trabalho de Conclusão de Curso (Graduação) Faculdade de Educação e Ciências Humanas de Anicuns - FECHA. Goiás. 2005.

FAÚNDES, A.; TORRES RODRIGUES, J. Aborto legal: implicações éticas e religiosas. 1. ed. São Paulo: Católicas pelo direito de decidir, 2002.

MDEMULHER. Aborto: depoimentos de quem fez. 2010. Disponível em: <http://mdemulher.abril.com.br/familia/aborto-depoimentos-de-quem-fez/>. Acesso em: 03 abr. 2017

NOGUEIRA, P. Em defesa da vida. 1. ed. São Paulo: Saraiva, 1995.

PRAGMATISMO POLÍTICO. 850 mil mulheres realizam aborto no Brasil por ano. 2014. Disponível em: <http://www.pragmatismopolitico.com.br/2014/09/850-mil-mulheres-realizam-aborto-brasilpor-ano.html>. Acesso em: 22 mar. 2017.

http://portal.aprendiz.uol.com.br/content/brasil-e-o-pais-em-que-mais-se-praticam-abortos

Acesso em: 10 ago. 2017. 